\title{
Case Report \\ Effects of isometric handgrip training in patients with cardiovascular disease: rationale and design of the ISOPRESS network
}

\author{
Breno Q. Farah ${ }^{1}$, Lauro C. Vianna ${ }^{2}$, Sergio Luiz C. Rodrigues ${ }^{3}$, Marilia A. Correia ${ }^{4}$, André L. Teixeira ${ }^{2}$, Flávio M. \\ D. de Andrade ${ }^{1,5}$, Rodrigo P. Pedrosa ${ }^{4}$, Sérgio R. Moreira ${ }^{6}$, Mauro V. G. Barros ${ }^{4}$, Nelson Wolosker ${ }^{7}$; Gabriel G. \\ Cucato $^{7}$; Raphael M. Ritti-Dias ${ }^{8}$ \\ ${ }^{1}$ Centro Universitária Tabosa de Almeida ASCES-UNITA, Caruaru, PE, Brazil, ${ }^{2}$ Universidade de Brasí- \\ lia, UNB, Brasília, DF, Brazil; ${ }^{3}$ Universidade Federal Rural de Pernambuco, UFRPE, Recife, PE, Brazil; ${ }^{4}$ Uni- \\ versidade de Pernambuco, UPE, Recife, PE, Brasil; ${ }^{5}$ Universidade Católica de Pernambuco, UNICAP, Reci- \\ fe, PE, Brazil; ${ }^{6}$ Universidade do Vale do São Francisco, UNIVASF, Petrolina, PE, Brazil; ${ }^{7}$ Hospital Israelita Al- \\ bert Einstein, São Paulo, SP, Brazil, ${ }^{8}$ Universidade Nove de Julho, UNINOVE, São Paulo, SP, Brazil
}

\begin{abstract}
Meta-analytical studies have indicated that isometric handgrip training promotes significant reduction in blood pressure in hypertensive patients with similar or greater decreases in blood pressure than observed after aerobic and dynamic resistance training. However, several gaps in the literature still need to be addressed. Thus, we designed the ISOPRESS network group, which consists of a task force of different research groups aimed at analyzing the effects of isometric handgrip training on different contexts, parameters, and populations. Thus, the aim of this study was to describe the rationale and design behind the ISOPRESS, presenting the methods employed. The ISOPRESS questions involve whether isometric handgrip training is effective in hypertensives in different settings (ISOPRESS 1 - unsupervised training and ISOPRESS 2 - public health system), whether it works in patients with other cardiovascular diseases (ISOPRESS 3 obstructive sleep apnea and ISOPRESS 4 - peripheral artery disease) and what are the mechanisms underlying the effects of isometric handgrip training in hypertensives (ISOPRESS 5 - neural mechanism). The study will yield information on the effectiveness of isometric handgrip training in different settings and patients with other cardiovascular diseases. Finally, it will help to understand the mechanisms involved in reducing blood pressure in hypertensives.
\end{abstract}

Keywords: research methods; hypertensive; isometric training; blood pressure; exercise

\section{Introduction}

Cardiovascular diseases (CVD) are the leading cause of death worldwide. It is estimated that $30 \%$ of deaths worldwide are a consequence these diseases ${ }^{1}$. The total direct and indirect cost of CVD in the United States for 2010 was estimated to be $\$ 315.4$ billion $^{2}$. It is known that there is a strong, independent relation between CVD morbidity, and mortality and hypertension ${ }^{2}$, with more than $50 \%$ of all CVD directly associated to hypertension ${ }^{1}$. Hypertension affects more than 1 billion people ${ }^{3}$, and in 2025, it is estimated that hypertension will affect more than 1.5 billion people worldwide ${ }^{4}$. Therefore, interventions to reduce blood pressure are sorely needed in order to reduce cardiovascular risk and the costs associated with high blood pressure.

Lifestyle modification programs are considered a cornerstone in therapeutic approach of CVD patients ${ }^{5-7}$, and a key recommendation is exercise. Aerobic exercises have been widely recommended for lowering blood pressure and they are complemented by dynamic resistance exercises ${ }^{5-7}$. Recently, meta-analytical studies ${ }^{8-13}$ demonstrated that isometric training, especially the handgrip ${ }^{13}$, decreases the office blood pressure, and a recent estimate showed reductions of approximately 7 $\mathrm{mmHg}$ for systolic and $5 \mathrm{mmHg}$ for diastolic in hypertensives ${ }^{14}$. These decreases are similar or greater than those observed after aerobic and dynamic resistance training ${ }^{10}$. Interestingly, isometric handgrip training is performed with a portable device, is easy to perform, requires less than 35 min per week ${ }^{5-7}$, and avoids important barriers for physical activity practice in patients with cardiovascular disease ${ }^{15,16}$. These aspects have piqued the interest of the scientific community to understand the potential of isometric handgrip training in the therapeutic approach of patients with CVD. However, the studies were performed only in hypertensive and normotensive patients, and analyzed only a few variables ${ }^{17,18}$.

In this context, we designed the ISOPRESS network group, which consists of a task force of different research groups in Brazil that aim to understand the effects, applicability and mechanisms of isometric handgrip exercise. For this, we will analyze the effects of isometric handgrip training on different populations (hypertensive, peripheral artery disease patients and obstructive sleep apnea patients) and contexts (ie clinical, unsupervised and laboratory). Thus, the aim of this study was to describe the rationale and design behind the ISOPRESS network, presenting the methods employed.

\section{Methods}

\section{Rationale}

The ISOPRESS network was developed to analyze the effects of isometric handgrip training on cardiovascular variables in 
different contexts and populations. The ISOPRESS network includes four Brazilian institutions that will address five different questions regarding handgrip exercise training. The questions involve whether isometric handgrip training is effective in different settings (ISOPRESS 1 and 2), whether it works on patients with other cardiovascular diseases (ISOPRESS 3 and 4) and what are the mechanisms underlying the effects of isometric handgrip training (ISOPRESS 5). These aspects are clarified in the figure 1.

Figure 1. Rationale of ISOPRESS network. OSA - Obstructive Sleep Apnea. PAD - Peripheral artery disease.

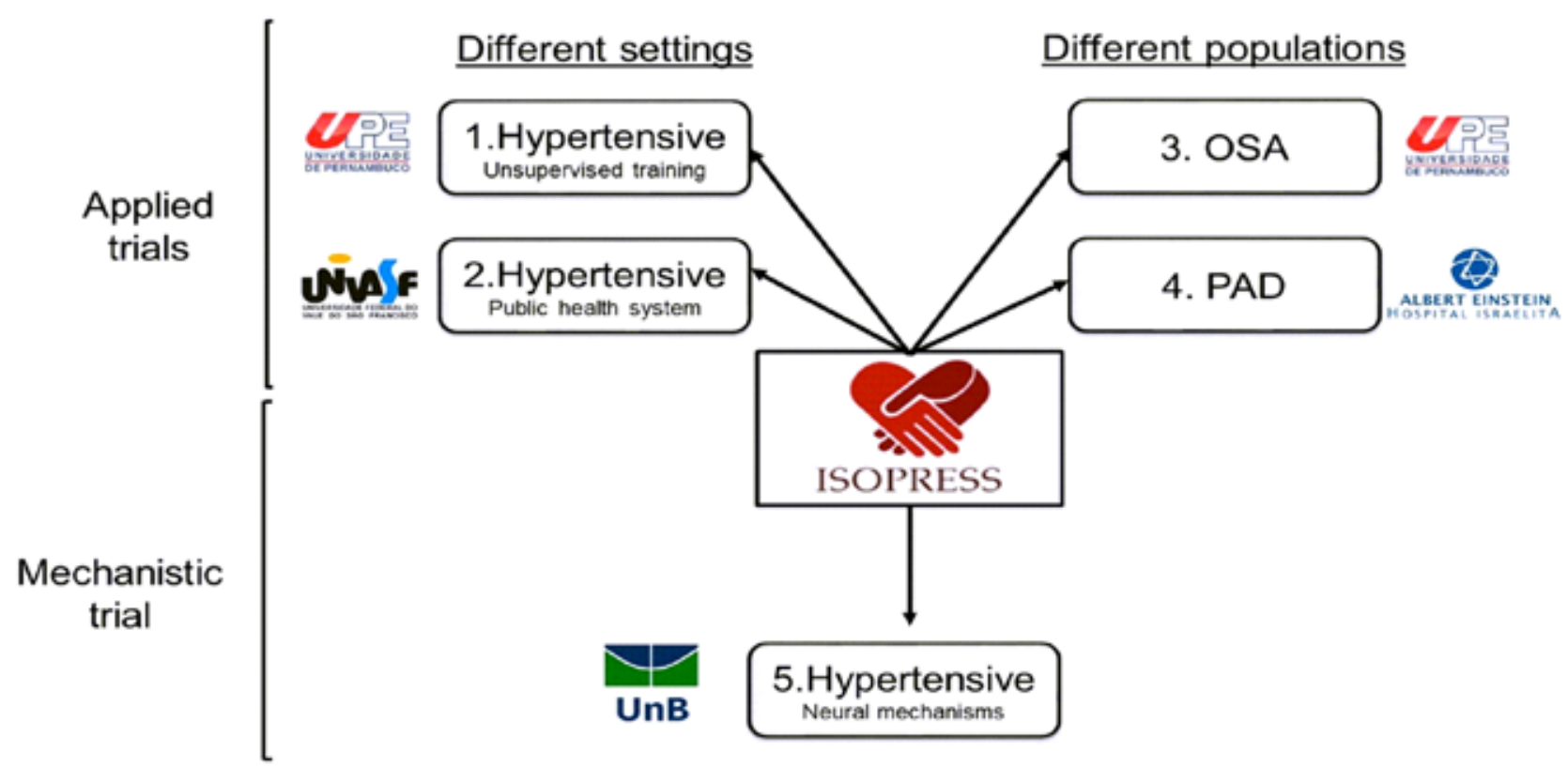

The importance of ISOPRESS 1 and 2 studies are that all studies using isometric handgrip training used the supervised training at laboratory. However, given that the handgrip is portable, easy to perform and requires short period of time to perform the exercise, the unsupervised training seems to be an interesting option of training at low cost. The ISOPRESS 3 and 4 are designed to analyze the effects of isometric handgrip training on patients with comorbid conditions, which are prevalent in adults (obstructive sleep apnea) ${ }^{19}$ and the elderly (peripheral artery disease $)^{20}$. Thus, the design will allow the understanding of isometric handgrip training on subjects with different severities of cardiovascular disease.

The mechanisms underlying the effects of isometric handgrip exercise are still unclear. Although some evidence has suggested the possible role of the autonomic nervous system ${ }^{21,22}$ and oxidative stress ${ }^{23}$, several pieces of the puzzle are missing. The purpose of ISOPRESS 5 is to analyze autonomic and vascular parameters as some of them were not previously described (barorreflex sensitivity). The characteristics of the studies developed in ISOPRESS project, as well as the guiding questions, sample involved, and settings are presented in Table 1.

Table 1. Characteristics of studies developed in ISOPRESS project.

\begin{tabular}{|c|c|c|c|}
\hline & Question & Sample & Setting \\
\hline Isopress 1 & $\begin{array}{c}\text { Are the effects of unsupervised isometric handgrip training } \\
\text { similar to supervised training? }\end{array}$ & Hypertensive & Unsupervised \\
\hline Isopress 2 & $\begin{array}{c}\text { Can isometric handgrip training decrease blood pressure in } \\
\text { patients attended in public health system? }\end{array}$ & Hypertensive & Public health system \\
\hline Isopress 3 & $\begin{array}{r}\text { Can isometric training reduce blood pressure in patients } \\
\text { with obstructive apnea syndrome? }\end{array}$ & Obstructive Sleep Apnea & Clinical \\
\hline Isopress 4 & $\begin{array}{r}\text { Can isometric training reduce blood pressure in patients } \\
\text { with vascular disease? }\end{array}$ & $\begin{array}{c}\text { Peripheral arterial disease } \\
\text { patients }\end{array}$ & Clinical \\
\hline Isopress 5 & $\begin{array}{c}\text { Does the autonomic modulation is involved in the reduction in } \\
\text { blood pressure with handgrip training? }\end{array}$ & Hypertensive & Laboratory \\
\hline
\end{tabular}




\section{Inclusion criteria:}

The inclusion and exclusion criteria vary between studies, depending on the specific aim of the study, as well as the specific characteristics of the studied sample. For example, peripheral artery disease patients present higher prevalent rates of cognitive impairment $\mathrm{t}^{24}$ and this could affect the unsupervised training. Patients with hypertension associated with diabetes or other cardiovascular diseases or neurological/cognitive diseases will not be included in studies with hypertensives (ISOPRESS 1, 2 and 5) in order to avoid chronic complications of these diseases. In all studies, patients will be excluded if they change their medication.

ISOPRESS 1: Age > 18 years old, both sexes, non-participation in exercise program: use of antihypertensive medication, availability to participate in any group.

ISOPRESS 2: Age > 18 years old, both sexes with controlled hypertension from antihypertensive medication. All subjects will be recruited individually in the family health centers.

ISOPRESS 3: Age from 30 to 65 years old, both sexes, with mid to moderate obstructive sleep apnea (apnea-hypopnea index 5-29 events/hour) and uncontrolled blood pressure (e.g. systolic blood pressure $>130 \mathrm{mmHg}$ and diastolic $>80 \mathrm{mmHg}$ in ambulatory blood pressure monitoring).

ISOPRESS 4: Age > 50 years old, if female, postmenopausal without hormone therapy replacement, ankle brachial index $<0.90$, in one or both lower limbs, insufficiently active, non-smoker, no diagnosis of neurological/ cognitive diseases.

ISOPRESS 5: Age > 18 years old, both sexes, non-participation in exercise program, not using antihypertensive, and non-smoking.

\section{Similarities and differences in exercise protocol}

All efforts were made to standardize the methodology among different studies. In all studies patients will be allocated in their groups according to random numbers generated on the website www.randomizer.org. In addition, the evaluators will be will not be seen by the group of the patients. All groups will perform four two minute' sets with $30 \%$ of maximum voluntary contraction. The training period will last between eight and twelve weeks.

In some cases, the standardization was violated to attend some specific aim of the study. For example, in ISOPRESS 4 , which includes peripheral artery disease patients, the understanding of local effects of training is important due to the systemic atherosclerotic process in these patients. Therefore, in this specific study, an unilateral exercise training will be performed, while in the other studies a bilateral protocol will be used. Although this difference may impact the comparisons, previous studies with unilateral training reported results similar to bilateral training ${ }^{25-27}$.

Another difference is the device used to perform training programs. The use of two devices will allow understanding the influence of different devices during isometric handgrip training on cardiovascular variables. The devices that will be used are: a) Zona Plus (Zona Health, Boise, Idaho, USA) and, b) Camry device (Zhongshan Camry Electronic Co. Ltd. Zhongshan Guangdong, China). There Zona plus is a digital dynamometer that was developed specifically for isometric handgrip training. In each session it records the maximal voluntary contraction, and then sets the load that need to be achieved in each set. The screen in the device provides an instantaneous feedback of the amount of force indicating if the amount of force applied is adequate. In addition, the device has a timer that provides information regarding the duration of exercise and the rest intervals. On the other hand, the Camry is a simple device that provides information regarding the amount of force supplied. Thus, the determination of the amount of strength, duration of the set and rest intervals should be actively performed by the volunteers. Figure 2 presents the two devices used in this study.

Finally, the control group will differ in some points between studies. In all studies patients randomized for the control group will be encouraged to increase their physical activity level and to have healthy eating habits. However, for ethical reasons, the patients attended in public health system (including peripheral artery disease patients) will receive specific recommendations to increase their amount of physical activities, as a way to improve their health. In all studies, the experimental group will receive the same lifestyle recommendations as the control group. Table 2 presents the details of interventions between studies.

Table 2. Details of interventions between studies in the ISOPRESS project.

\begin{tabular}{|c|c|c|c|c|}
\hline & Protocol & Supervision & Device & Control \\
\hline Isopress 1 & Bilateral & No & Camry & Improve lifestyle habits \\
\hline Isopress 2 & Bilateral & No & Camry & Achieve 5000 steps/day \\
\hline Isopress 3 & Bilateral & Yes & Zona Plus & Achieve 5000 steps/day \\
\hline Isopress 4 & Unilateral & No lifestyle habits \\
\hline Isopress 5 & Bilateral & Yes & Zona Plus & Improve lifestyle habits \\
\hline
\end{tabular}


Figure 2. Devices will be used in the ISOPRESS project. A - Zona Plus device; B - Camry device.
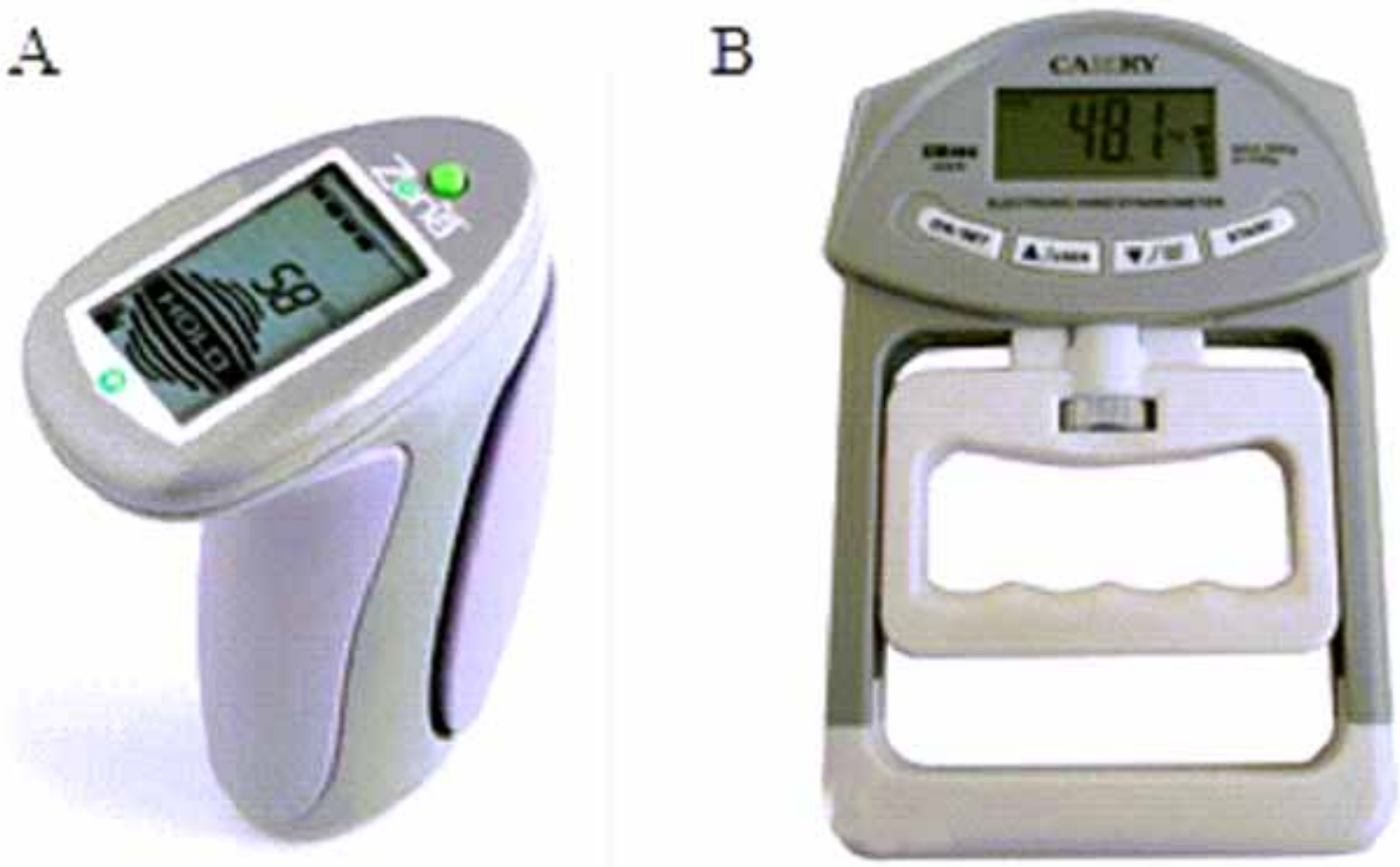

\section{Variables analyzed}

Table 3 lists the variables obtained in the studies. The measures are standardized between all studies. Prior to all cardiovascular

variables measurements, the patients will be instructed to avoid physical exercise for at least 24 hours prior to the visit, avoid smoking, alcohol and caffeine ingestion for at least 12 hours and to eat a light meal before arriving at the laboratory.

Table 3. Outcomes assessments of ISOPRESS project.

\begin{tabular}{|c|c|c|c|c|c|}
\hline Variables & ISOPRESS 1 & ISOPRESS 2 & ISOPRESS 3 & ISOPRESS 4 & ISOPRESS 5 \\
\hline Office blood pressure & $\mathbf{X}$ & $\mathbf{X}$ & $\mathbf{X}$ & $\mathbf{X}$ & $\mathbf{X}$ \\
\hline Ambulatory blood pressure & $\mathbf{X}$ & $\mathbf{X}$ & - & - & - \\
\hline Central blood pressure & $\mathbf{X}$ & - & $\mathbf{X}$ & $\mathbf{X}$ & - \\
\hline Ankle brachial index & $\mathbf{X}$ & - & - & - & - \\
\hline \multicolumn{6}{|l|}{ Cardiac autonomic modulation } \\
\hline Heart rate variability & $\mathbf{X}$ & - & - & $\mathbf{X}$ & - \\
\hline Blood pressure variability & & & & & $\mathrm{X}$ \\
\hline Central sympathetic activity & - & - & - & - & $\mathbf{X}$ \\
\hline \multicolumn{6}{|l|}{ Baroreflex sensitivity } \\
\hline Non-pharmacological approach & - & - & - & - & $\mathbf{X}$ \\
\hline Pharmacological approach & - & - & - & - & $\mathbf{X}$ \\
\hline Arterial stiffness measures & $\mathbf{X}$ & - & $\mathbf{X}$ & $\mathbf{X}$ & - \\
\hline Vascular measures & $\mathbf{X}$ & - & $\mathbf{X}$ & $\mathbf{X}$ & - \\
\hline Biomarkers & $\mathbf{X}$ & - & - & - & - \\
\hline
\end{tabular}




\section{Office blood pressure}

Office blood pressure will be performed through the Omron HEM 742 device. For this, individuals remain for ten minutes in the supine position. Three consecutive measurements will be performed with one-minute intervals at higher arm pressure and with the proper cuff size to arm circumference. The value used is the average of the last two measures ${ }^{6}$.

\section{Ambulatory blood pressure monitoring (ABPM)}

The ambulatory blood pressure readings over a 24-hour period will be obtained using the oscillometric device (Dyna-MAPA, Cardios, Brazil) programmed to take measurements every 15 minutes during the daytime and every 30 minutes at night time. The individual will be oriented to log on a specific form any abnormal occurrence (daily or nightly), during the use of the device. Additionally, the person will be instructed to not drink alcoholic beverages, to not practice physical exercise and to not sleep during the day on the 24 hours under evaluation. The exam through the MABP will only be considered acceptable for the study if at least $85 \%$ of the possible measures for the 24 hours of monitoring are successfully obtained. Thus, the average and the standard deviation of the 24 hours of systolic, diastolic and mean blood pressure will be obtained, which also will be subdivided into waking and sleeping periods. The nocturnal drop in blood pressure will be calculated in absolute terms (mean waking mean sleeping blood pressure), which will be obtained by the mean of the values reported in the period that the patients will be awake and sleep, respectively; while the morning surge will be calculated as the difference between the mean blood pressure during the last two hours of sleep and that of the first two hours after waking. The 24-hour awake and asleep pressure loads will be calculated by the percentage of measurements with values greater than $125 / 75,130 / 85$ and $110 / 70 \mathrm{mmHg}$, respectively ${ }^{6}$.

\section{Central blood pressure}

Central systolic and diastolic blood pressure will be obtained by pulse wave analysis recorded in the left radial artery using applanation tonometry (SphygmoCor, AtCor Medical, Australia) and the validated transfer function algorithm provided by the Sphygmocor ${ }^{\circledR}$ software will obtain the central values of systolic, diastolic, and mean blood pressures, equivalent to the pressure wave measured by an invasive catheter ${ }^{28}$. To enhance the accuracy of measurements, only those values that had a quality index over $90 \%$ will be used.

\section{Ankle brachial index}

The ankle brachial index will be measured as the highest systolic blood pressure in the posterior tibial artery or dorsalis pedis artery divided by the highest systolic blood pressure in the brachial artery ${ }^{29}$. The measurement of blood pressure in the ankle and arm will be measured in triplicate, using Doppler vascular (Medmega DV160, Brazil) and a mercury sphygmomanometer, respectively.

\section{Cardiac autonomic modulation}

\section{Blood pressure variability}

Continuous beat-to-beat arterial blood pressure will be measured using finger photoplethysmography (Human NIBP Controller, $\mathrm{AD}$ instruments, Australia). After at least ten minutes of resting, ten minutes of consecutives beats will be recorded. Spectral analysis of blood pressure will be performed employing the CardioSeries v2.4 software, which uses Fourier transformation to calculate spectral power systolic blood pressure variability. Blood pressure variability will be calculated after appropriate spline interpolation and equidistant representation of systolic blood pressure data. The very low frequency (VLF) band will be defined in the range of $0.02-0.07 \mathrm{~Hz}$, the low frequency (LF) band in the area of $0.07-0.15 \mathrm{~Hz}$, and the high frequency (HF) band between 0.15 and $0.40 \mathrm{~Hz}$. The LF component of blood pressure variability will be used as a proxy of the sympathetic modulation of the vascular tone ${ }^{30}$.

\section{Heart rate variability}

Heart rate variability (HRV) will be assessed from the RR intervals obtained by a heart rate monitor (RS800CX, Polar Electro, Finland). Patients will remain in the supine position for 10 minutes and, after approximately 30 minutes at rest, next, at least five minutes of the stationary period will be used for analysis. All analysis will be performed with Kubios HRV software (Biosignal Analysis and Medical Imaging Group, Joensuu, Finland) by a single evaluator blinded to the other study variables. The intraclass correlation coefficient of this measure in our lab ranged 0.990 to $0.993^{31}$, following the recommendations of the Task Force of $\mathrm{HRV}^{32}$.

The time-domain parameters, such as: standard deviation of all RR intervals (SDNN), root mean square of the squared differences between adjacent normal RR intervals (RMSSD), and the percentage of adjacent intervals over 50ms (PNN50) will be obtained. The frequency-domain parameters will be analyzed using the spectral analysis of HRV. Stationary periods of the tachogram will be broken down into bands LF and high HF frequencies, using the autoregressive method with a fixed model order of 12 by Akaike's information criterion. Frequencies between 0.04 and $0.4 \mathrm{~Hz}$ were considered as physiologically significant, where the LF component was represented by oscillations between 0.04 and $0.15 \mathrm{~Hz}$ and $\mathrm{HF}$ was represented by oscillations between 0.15 and $0.4 \mathrm{~Hz}$. The power of each spectral component was normalized by dividing the power of each spectrum band by the total variance, minus the value of very low frequency band $(<0.04 \mathrm{~Hz})$, and multiplying the result by 100 .

Non-linear parameters, such as: Poincare plot (SD1 and SD2), Recurrence plot (Mean line length - Leman, Max line length - Lmáx, Recurrence rate - REC, Determinism - DET, 
Shannon Entropy - ShanEn) and other parameters such as approximate entropy (ApEn), Sample entropy (SampEn), $\alpha 1, \alpha 2$ and correlation dimension (D2) will be obtained.

\section{Central sympathetic activity}

Postganglionic multiunit muscle sympathetic nerve activity (MSNA) will be obtained using a unipolar tungsten microelectrode inserted in the peroneal nerve of the right leg at the fibular head, and a reference electrode will be placed subcutaneously $2-3 \mathrm{~cm}$ distal. The recording electrode will adjust until a site is found where nerve unit activity displays a pulse-synchronous pattern of spontaneous bursts, with a signal-to-noise ratio of $3: 1$, are increased during an end-expiratory breath-hold or Valsalva maneuver, and are unresponsive to an unexpected loud noise or skin stroking ${ }^{33}$. The raw signal will be amplified $(\times 100,000)$, filtered (bandwidth $700-2,000 \mathrm{~Hz})$, rectified, and integrated (time constant $0.1 \mathrm{~s}$ ) to obtain a mean voltage neurogram (Iowa Bioengineering, Iowa City, IA). Sympathetic bursts will be identified using a fully automated program ${ }^{34}$. The mean voltage neurogram will be normalized by calibrating the height of the largest set of bursts during baseline to a value of 1,000 arbitrary integration units (AU). MSNA will be quantified as burst incidence (bursts/100 heart beats), burst frequency (bursts/ min), and MSNA total activity (AU).

\section{Baroreflex sensitivity}

\section{Non-pharmacological approach}

Continuous beat-to-beat arterial blood pressure will be measured using finger photoplethysmography (Human NIBP Controller, $\mathrm{AD}$ instruments, Australia). After at least ten minutes of resting, ten minutes of consecutives beats will be recorded.

Beat-to-beat time series of systolic blood pressure and RR intervals will be analyzed using the sequence technique for estimating spontaneous cardiac baroreflex sensitivity (cBRS; CardioSeries v2.4, Brazil). Briefly, sequences of three or more consecutive beats with corresponding increases or decreases in systolic blood pressure and RR interval will be identified as arterial baroreflex sequences. Sequences will be detected only when the variation in RR intervals is greater than $1.0 \mathrm{~ms}$, and when systolic blood pressure changes are greater than $1 \mathrm{mmHg}$, and longer than 3 consecutive cardiac cycles. A linear regression will be applied to each individual sequence and only those sequences in which $R^{2}$ was $>0.85$ will be accepted. The slopes of the systolic blood pressure and RR interval relationships are then calculated and averaged for a measure of spontaneous cBRS. The sequence technique is based on the identification of sequences of consecutive beats in which progressive increases in systolic BP are followed by a progressive lengthening in RR intervals or vice versa; progressive decreases in systolic blood pressure are followed by a progressive shortening in RR intervals.

In addition, the baroreflex effectiveness index (BEI) will be calculated $^{34}$. BEI is defined as the ratio between the number of systolic blood pressure ramps followed by the respective reflex RR interval ramps and the total number of systolic blood pressure ramps observed in a given time window.

\section{Pharmacological approach}

The baroreflex sensitivity sequence technique will also be evaluated during episodes of rise and fall in blood pressure. The rapid and abrupt change in blood pressure will be induced using a pharmacological model. In this procedure transient hypotension and hypertension (always in this order) will be induced by intravenous bolus injections of sodium nitroprusside (150 to $300 \mu \mathrm{g}$ ) and phenylephrine hydrochloride (200 to $400 \mu \mathrm{g}$ ).

\section{Arterial stiffness measures}

Pulse wave velocity will be measured using high-fidelity applanation tonometry (Sphygmocor, ATCOR Medical, Australia) following the guidelines of the Clinical Application of Arterial Stiffness, Task Force $\mathrm{III}^{35}$. For the central pulse wave velocity, the distance between carotid artery to the suprasternal notch and femoral artery to the suprasternal notch will be measured using a standard tape. Then, the distance between the two arteries will be divided by the time difference. Simultaneous EKG will be assessed to obtain heart rate and, according to a "foot-to-foot" method, the time difference between the points will be measured.

Aortic blood pressure and reflected wave indicators - augmentation index, augmentation index $75 \mathrm{bpm}$, and aortic pulse pressure - will be estimated in the radial artery using the applanation tonometry technique (Sphygmocor, ATCOR Medical Australia), and the validated transfer function provided by the Sphygmocor ${ }^{\circledR}$ software. Pulse pressure will be obtained by the difference between the systolic and diastolic pressure in the radial artery using the applanation tonometry technique.

The ambulatory arterial stiffness index which will be defined as 1 minus the regression slope, from individual 24-hour recordings, and it will be computed the regression slope of diastolic pressure on systolic blood pressure.

\section{Vascular measurements}

Blood flow and flow-mediated dilation measurements will be obtained by ultrasound according to recent recommendations $\mathrm{s}^{36,37}$. A two-dimensional ultrasound machine will record images of the brachial artery with spectral Doppler and linear transducer (Ultra-0122, Philips, The Netherlands).

For that, each patient should lie comfortably in the supine position for at least 20 minutes of rest with the arm slightly abducted. After locating the brachial artery, the transducer will be placed on the distal third of the arm (2-12 $\mathrm{cm}$ above the antecubital fossa). To confirm to the good location and the quality of the arterial pulse obtained, the Doppler sound will be activated. The contrast resolution, depth, and gain will be adjusted to optimize the longitudinal images of the lumen/arterial 
wall interface. Brachial artery diameter and insonation anglecorrected at $60^{\circ}$, blood velocity spectra will be simultaneously recorded via the pulsed-wave mode at linear frequencies of 13 and $6.0 \mathrm{MHz}$, respectively.

Baseline diameter and blood velocity waveforms will be continuously recorded over $120 \mathrm{~s}$. After that, a cuff, placed on the forearm, will be inflated with a pressure above $50 \mathrm{~mm} \mathrm{Hg}$ of the systolic blood pressure measured before the examination. The occlusion will be maintained for five minutes, and, after this period, rapidly released. The Doppler recordings will be resumed $30 \mathrm{~s}$ before deflation and will maintain for $180 \mathrm{~s}$ after. The diameter of the brachial artery and post-occlusion of blood flow velocity will be measured after the release. The vasodilatory capacity will be calculated by the flow-mediated dilation, the percentage of increase in diameter of the brachial artery post occlusion compared to their baseline values.

In addition, the carotid intima-media thickness will be obtained. For this, the ultrasound will be used in accordance with previous recommendations ${ }^{38}$. A two-dimensional ultrasound machine will record images with spectral Doppler and linear transducer (Ultra-0122, Philips, The Netherlands). The contrast resolution, depth $(3-4 \mathrm{~cm})$, frequency $(>15 \mathrm{~Hz})$ and gain will be adjusted to optimize the longitudinal images of the arterial wall interface. The measures will be carried out in triplicate, before the carotid artery bifurcation and at the end of diastole.
The intima-media thickness of carotid artery is given by the average thickness of the selected image.

\section{Biomarkers}

Blood samples $(4 \mathrm{ml})$ will be collected in tubes containing EDTA, homogenised by inversion, and then will be centrifuged at 1500 rpm for $15 \mathrm{~min}$. Thereafter, the plasma will be separated, placed in Eppendorf tubes, and kept at $-80^{\circ} \mathrm{C}$ until analysis. Blood will be analyzed for oxidative stress and inflammation markers. The oxidative stress marker will be analyzed as advanced oxidized protein products (AOPP), which reflects protein oxidation of inflammatory nature and malondialdehyde (MDA), a final product of the lipoperoxidation reaction. The inflammation markers will be analyszd are: interleukin-1 $\beta$ (IL-1 $\beta$ ), interleukin-10 (IL-10), interleukin-6 (IL-6), tumor necrosis factor- $\alpha$ (TNF- $\alpha$ ), $\mathrm{C}$-reactive protein (CRP) will be performed in plasma samples using available commercial kits, following the manufacturers' instructions (Invitrogen, California USA).

\section{Schedule}

In table 4 is described the schedule for execution of each study ISOPRESS network.

Table 4. Schedule of each study of ISOPRESS network.

\begin{tabular}{|c|c|c|c|c|c|c|c|c|c|c|c|c|c|c|c|c|c|c|c|c|}
\hline & \multicolumn{4}{|c|}{ ISOPRESS 1} & \multicolumn{4}{|c|}{ ISOPRESS 2} & \multicolumn{4}{|c|}{ ISOPRESS 3} & \multicolumn{4}{|c|}{ ISOPRESS 4} & \multicolumn{4}{|c|}{ ISOPRESS 5} \\
\hline & 2015 & 2016 & 2017 & 2018 & 2015 & 2016 & 2017 & 2018 & 2015 & 2016 & 2017 & 2018 & 2015 & 2016 & 2017 & 2018 & 2015 & 2016 & 2017 & 2018 \\
\hline $\begin{array}{c}\text { Staff } \\
\text { training }\end{array}$ & $X$ & & & & & $X$ & & & & $X$ & & & & $\mathrm{X}$ & & & $X$ & & & \\
\hline Recruitment & $\mathrm{X}$ & $\mathrm{X}$ & & & & $\mathrm{X}$ & $\mathrm{X}$ & & & $\mathrm{X}$ & & & & $\mathrm{X}$ & & & $\mathrm{X}$ & $\mathrm{X}$ & & \\
\hline Intervention & $\mathrm{X}$ & $\mathrm{X}$ & & & & $\mathrm{X}$ & $\mathrm{X}$ & $\mathrm{X}$ & & & $\mathrm{X}$ & & & $\mathrm{X}$ & & & $X$ & $\mathrm{X}$ & & \\
\hline $\begin{array}{c}\text { Data } \\
\text { analysis }\end{array}$ & & $X$ & $\mathrm{X}$ & & & & $\mathrm{X}$ & $\mathrm{X}$ & & & $\mathrm{X}$ & $X$ & & $\mathrm{X}$ & $\mathrm{X}$ & $\mathrm{X}$ & & $\mathrm{X}$ & $\mathrm{X}$ & \\
\hline $\begin{array}{l}\text { Submission } \\
\text { of } \\
\text { manuscripts }\end{array}$ & & $X$ & $X$ & $\mathrm{X}$ & & & $\mathrm{X}$ & $\mathrm{X}$ & & & $X$ & $\mathrm{X}$ & & $\mathrm{X}$ & $\mathrm{X}$ & $X$ & & $\mathrm{X}$ & $\mathrm{X}$ & $\mathrm{X}$ \\
\hline
\end{tabular}

\section{Ethical issues}

All procedures of the ISOPRESS network were approved by the Institutional Review Board at each institution in which the studies will be developed. All procedures followed the Brazilian National Research Ethics System Guidelines and with the Helsinki Declaration of 1975 (revised in 1983). A written informed consent form was obtained from each patient before participation.

\section{Statistical issues}

\section{Analysis}

Normality and homogeneity of variance of data will be confirmed by Shapiro-Wilks and Levene tests, respectively. The analysis of the effects of isometric handgrip training on cardiovascular variables (table 1) will be made in line with the intention-totreat principle through comparison of the changes in the main outcomes between experimental and control groups. If the data does not meet the parametric premises, a nonparametric equivalent test will be used. An $\alpha$-level of $<0.05$ will be used to establish statistical significance in all analyses.

\section{Power calculation}

To determine sample size, previously published data on the mean reduction and standard deviation of systolic blood pressure (our primary endpoint) following isometric handgrip training ${ }^{39}$ will be used. From this work, we anticipated the smallest meaningful difference and standard deviation in systolic blood pressure 
following isometric handgrip training to be $6 \pm 4.6 \mathrm{mmHg}$. Based on an assigned $\alpha$ of 0.05 and $\beta$ of 0.2 , an estimate of the least nine participants per group was deemed sufficient. However, depending on the objective of each study larger sample sizes may be required.

\section{Discussion}

Isometric handgrip training has been considered a promising intervention to reduce cardiovascular risk in adults, given the positive effects on cardiovascular variables. Recent meta-analytical study showed a reduction in systolic blood pressure of $5 \mathrm{mmHg}$ in hypertensives ${ }^{13}$. Another advantage of the handgrip exercise is its easy implementation that allows it to be carried anywhere, including at home.

However, the following gaps have not been measured: the mechanisms responsible for the reduction of blood pressure after isometric handgrip training in hypertensives; the effects of unsupervised training in clinical and public system settings; the effects this type of exercise in other populations with hypertension and associated diseases. These gaps will be addressed in the ISOPRESS network, including five studies performed in different research groups.

The main challenges of the ISOPRESS project are: (i) the feasibility of unsupervised handgrip training is unknown, and an attenuation of the effects of training is expected; (ii) the lack of effects in obstructive sleep apnea and peripheral artery disease symptoms may also make the adherence to training difficult; (iii) the methods used for the mechanical approach is invasive and some individuals may refuse to carry out the study

The ISOPRESS network is an innovative way to understanding the potential of handgrip exercise to control cardiovascular risk in CVD patients. The evaluation of neural and vascular mechanisms provide an important to elucidate the range of options that isometric handgrip training can reduce blood pressure. In practical terms, the results will facilitate the understanding of whether this promising mode of exercise that requires only 33 minutes a week of practice is effective in clinical settings. These aspects can be an interesting strategy for application in public health.

\section{REFERENCES}

1. World Health Organization. Cardiovascular diseases [Fact sheet \#317]. Geneva: WHO2013.

2. Go AS, Mozaffarian D, Roger VL, Benjamin EJ, Berry JD, Borden WB, et al. Heart disease and stroke statistics--2013 update: a report from the American Heart Association. Circulation. 2013;127(1):e6-e245.

3. Franco V, Oparil S, Carretero OA. Hypertensive Therapy: Part I. Circulation. 2004;109(24):2953-8.

4. Kearney PM, Whelton M, Reynolds K, Muntner P, Whelton PK, He J. Global burden of hypertension: analysis of worldwide data. Lancet. 2005;365(9455):217-23.
5. Mancia G, Fagard R, Narkiewicz K, Redon J, Zanchetti A, Bohm $\mathrm{M}$, et al. $2013 \mathrm{ESH} / \mathrm{ESC}$ guidelines for the management of arterial hypertension: the Task Force for the Management of Arterial Hypertension of the European Society of Hypertension (ESH) and of the European Society of Cardiology (ESC). Eur. Heart J. 2013;34(28):2159-219.

6. [VI Brazilian Guidelines on Hypertension]. Arq Bras Cardiol. 2010;95(1 Suppl):1-51.

7. James PA, Oparil S, Carter BL, Cushman WC, DennisonHimmelfarb C, Handler J, et al. 2014 evidence-based guideline for the management of high blood pressure in adults: report from the panel members appointed to the Eighth Joint National Committee (JNC 8). Jama. 2014;311(5):507-20.

8. Carlson DJ, Dieberg G, Hess NC, Millar PJ, Smart NA. Isometric exercise training for blood pressure management: a systematic review and meta-analysis. Mayo Clin Proc. 2014;89(3):327-34.

9. Kelley GA, Kelley KS. Isometric handgrip exercise and resting blood pressure: a meta-analysis of randomized controlled trials. J Hypertens. 2010;28(3):411-8.

10. Cornelissen VA, Smart NA. Exercise training for blood pressure: a systematic review and meta-analysis. J Am Heart Assoc. 2013;2(1):e004473.

11. Cornelissen VA, Fagard RH, Coeckelberghs E, Vanhees L. Impact of resistance training on blood pressure and other cardiovascular risk factors: a meta-analysis of randomized, controlled trials. Hypertension. 2011;58(5):950-8.

12. Owen A, Wiles J, Swaine I. Effect of isometric exercise on resting blood pressure: a meta analysis. J Hum Hypertens. 2010;24(12):796-800.

13. Inder JD, Carlson DJ, Dieberg G, McFarlane JR, Hess NC, Smart NA. Isometric exercise training for blood pressure management: a systematic review and meta-analysis to optimize benefit. Hypertens Res. 2016;39(2):88-94.

14. Jin YZ, Yan S, Yuan WX. Effect of isometric handgrip training on resting blood pressure in adults: a meta-analysis of randomized controlled trials. J Sports Med Phys Fitness. 2017;57(1-2):154-60.

15. Barbosa JP, Farah BQ, Chehuen M, Cucato GG, Farias Junior JC, Wolosker N, et al. Barriers to physical activity in patients with intermittent claudication. IJBM. 2015;22(1):70-6.

16. Godin G, Desharnais R, Valoi P, Lepage P, Jobin J, Bradet R. Differences in perceived barriers to exercise between high and low intenders:observations among different populations. Am J Health Promot. 1994;8:279-85.

17. Farah B, Germano-Soares A, Rodrigues S, Santos C, Barbosa S, Vianna L, et al. Acute and Chronic Effects of Isometric Handgrip Exercise on Cardiovascular Variables in Hypertensive Patients: A Systematic Review. Sports. 2017;5(3):55.

18. Millar PJ, McGowan CL, Cornelissen VA, Araujo CG, Swaine IL. Evidence for the role of isometric exercise training in reducing blood pressure: potential mechanisms and future directions. Sports Med. 19.

19. Pedrosa RP, Drager LF, Gonzaga CC, Sousa MG, de Paula LK, Amaro AC, et al. Obstructive sleep apnea: the most common secondary cause of hypertension associated with resistant hypertension. Hypertension. 2011;58(5):811-7.

20. Fowkes FG, Rudan D, Rudan I, Aboyans V, Denenberg JO, McDermott MM, et al. Comparison of global estimates of 
prevalence and risk factors for peripheral artery disease in 2000 and 2010: a systematic review and analysis. Lancet. 2013;382(9901):1329-40.

21. Taylor AC, McCartney N, Kamath MV, Wiley RL. Isometric training lowers resting blood pressure and modulates autonomic control. Med Sci Sports Exe. 2003;35(2):251-6.

22. Millar PJ, Levy AS, McGowan CL, McCartney N, MacDonald MJ. Isometric handgrip training lowers blood pressure and increases heart rate complexity in medicated hypertensive patients. Scand J Med Sci Sports. 2013;23(5):620-6.

23. Peters PG, Alessio HM, Hagerman AE, Ashton T, Nagy S, Wiley RL. Short-term isometric exercise reduces systolic blood pressure in hypertensive adults: possible role of reactive oxygen species. Int J Cardiol. 2006;110(2):199-205.

24. Guerchet M, Aboyans V, Nubukpo P, Lacroix P, Clement JP, Preux PM. Ankle-brachial index as a marker of cognitive impairment and dementia in general population. A systematic review. Atherosclerosis. 2011;216(2):251-7.

25. Badrov MB, Bartol CL, DiBartolomeo MA, Millar PJ, McNevin $\mathrm{NH}, \mathrm{McGowan} \mathrm{CL}$. Effects of isometric handgrip training dose on resting blood pressure and resistance vessel endothelial function in normotensive women. Eur J Appl Physiol. 2013;113(8):2091-100.

26. McGowan CL, Visocchi A, Faulkner M, Verduyn R, Rakobowchuk $\mathrm{M}$, Levy AS, et al. Isometric handgrip training improves local flow-mediated dilation in medicated hypertensives. E Eur J Appl Physiol. 2006;98(4):355-62.

27. Wiley RL, Dunn CL, Cox RH, Hueppchen NA, Scott MS. Isometric exercise training lowers resting blood pressure. Med Sci Sports Exe. 1992;24(7):749-54.

28. Siebenhofer A, Kemp C, Sutton A, Williams B. The reproducibility of central aortic blood pressure measurements in healthy subjects using applanation tonometry and sphygmocardiography. J Hum Hypertens. 1999;13(9):625-9.

29. Gardner AW, Montgomery PS. Comparison of three blood pressure methods used for determining ankle/brachial index in patients with intermittent claudication. Angiology. 1998;49(9):723-8.

30. Stauss HM. Identification of blood pressure control mechanisms by power spectral analysis. Clin Exp Pharmacol Physiol. 2007;34(4):362-8.

31. Farah BQ, Lima AH, Cavalcante BR, de Oliveira LM, Brito AL, de Barros MV, et al. Intra-individuals and inter- and intra-observer reliability of short-term heart rate variability in adolescents. Clin Physiol Funct Imag. 2016;36(1):33-9.

32. Heart rate variability: standards of measurement, physiological interpretation and clinical use. Task Force of the European Society of Cardiology and the North American Society of Pacing and Electrophysiology. Circulation. 1996;93(5):1043-65.

33. Vallbo AB, Hagbarth KE, Torebjork HE, Wallin BG. Somatosensory, proprioceptive, and sympathetic activity in human peripheral nerves. Physiol Rev. 1979;59(4):919-57.
34. Hamner JW, Taylor JA. Automated quantification of sympathetic beat-by-beat activity, independent of signal quality. J Appl Physiol. 2001;91(3):1199-206.

35. Van Bortel LM, Duprez D, Starmans-Kool MJ, Safar ME, Giannattasio C, Cockcroft J, et al. Clinical applications of arterial stiffness, Task Force III: recommendations for user procedures. Am J Hypertens. 2002;15(5):445-52.

36. Harris RA, Nishiyama SK, Wray DW, Richardson RS. Ultrasound assessment of flow-mediated dilation. Hypertension. 2010;55(5):1075-85.

37. Thijssen DH, Black MA, Pyke KE, Padilla J, Atkinson G, Harris RA, et al. Assessment of flow-mediated dilation in humans: a methodological and physiological guideline. Am J Physiol Heart Circ Physiol. 2011;300(1):H2-12.

38. Stein JH, Korcarz CE, Hurst RT, Lonn E, Kendall CB, Mohler $\mathrm{ER}$, et al. Use of carotid ultrasound to identify subclinical vascular disease and evaluate cardiovascular disease risk: a consensus statement from the American Society of Echocardiography Carotid Intima-Media Thickness Task Force. Endorsed by the Society for Vascular Medicine. J Am Soc Echocardiogr008;21(2):93-1110.

39. McGowan CL, Visocchi A, Faulkner M, Verduyn R, Rakobowchuk M, Levy AS, et al. Isometric handgrip training improves local flow-mediated dilation in medicated hypertensives. Eur J Appl Physiol. 2007;99(3):227-34.

\section{Acknowledgements}

The studies included in Isopress Network were funded by the Conselho nacional de Desenvolvimento Científico e Tecnológico (CNPQ, process: \#448759/2014- 4), Fundação de Apoio à Pesquisa do Distrito Federal - FAP-DF (193.000.652/2015 - 193.000828/2015, Fundação de Amparo à Ciência e Tecnologia do Estado de Pernambuco (FACEPE, process: APQ 1177-4.09/14), Fundação de Amparo à Pesquisa do Estado de São Paulo (FAPESP, process: 2016/16425-9)

\section{Corresponding author}

Raphael Mendes Ritti-Dias, PhD. Rua Vergueiro, 235/249, $2^{\circ}$ Subsolo, Liberdade, São Paulo, SP.

Email: raphaelritti@gmail.com

Manuscript received on August 3, 2017

Manuscript accepted on November 27, 2017

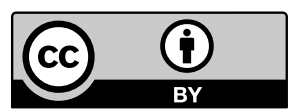

Motriz. The Journal of Physical Education. UNESP. Rio Claro, SP, Brazil - eISSN: 1980-6574 - under a license Creative Commons - Version 4.0 
ERRATUM

In the article "Effects of isometric handgrip training in patients with cardiovascular disease: rationale and design of the ISOPRESS network", DOI: http://dx.doi.org/10.1590/S1980-6574201700040011, published in Motriz Journal, vol. 23(4): e101719, 2017.

\section{Where it was written}

Breno Q. Farah ${ }^{1,2}$, Lauro C. Vianna ${ }^{3}$, Sergio Luiz C. Rodrigues ${ }^{1}$, Marilia A. Correia ${ }^{1}$, André L. Teixeira ${ }^{3}$, Flávio M. D. de Andrade ${ }^{4}$, Rodrigo P. Pedrosa ${ }^{1}$, Sérgio R. Moreira ${ }^{5}$, Mauro V. G. Barros ${ }^{1}$, Nelson Wolosker ${ }^{6}$; Gabriel G.

$$
\text { Cucato }^{6} \text {; Raphael M. Ritti-Dias }{ }^{6,7}
$$

${ }^{1}$ Universidade Federal Rural de Pernambuco, UFRPE, Recife, PE, Brazil; ${ }^{2}$ ASCES College, Caruaru, PE, Brazil;

${ }^{3}$ Universidade de Brasília, UNB, Brasília, DF, Brazil; ${ }^{4}$ Universidade Católica de Pernambuco, PUC, Reci-

fe, PE, Brazil; ${ }^{5}$ Universidade do Vale do São Francisco, UNIVASF, Petrolina, PE, Brazil; ${ }^{6}$ Hospital Israelita Albert Einstein, São Paulo, SP, Brazil; ; ${ }^{7}$ Universidade Nove de Julho, UNINOVE, São Paulo, SP, Brazil

\section{Should read}

Breno Q. Farah ${ }^{1}$, Lauro C. Vianna², Sergio Luiz C. Rodrigues ${ }^{3}$, Marilia A. Correia ${ }^{4}$, André L. Teixeira² , Flávio M. D. de Andrade ${ }^{1,5}$, Rodrigo P. Pedrosa ${ }^{4}$, Sérgio R. Moreira ${ }^{6}$, Mauro V. G. Barros ${ }^{4}$, Nelson Wolosker ${ }^{7}$; Gabriel G. Cucato $^{7}$; Raphael M. Ritti-Dias ${ }^{8}$

${ }^{1}$ Centro Universitária Tabosa de Almeida ASCES-UNITA, Caruaru, PE, Brazil, ${ }^{2}$ Universidade de Brasília, UNB, Brasília, DF, Brazil; ${ }^{3}$ Universidade Federal Rural de Pernambuco, UFRPE, Recife, PE, Brazil; ${ }^{4} U n i-$ versidade de Pernambuco, UPE, Recife, PE, Brasil, ${ }^{5}$ Universidade Católica de Pernambuco, UNICAP, Recife, PE, Brazil; ${ }^{6}$ Universidade do Vale do São Francisco, UNIVASF, Petrolina, PE, Brazil; ${ }^{7}$ Hospital Israelita Albert Einstein, São Paulo, SP, Brazil; ${ }^{8}$ Universidade Nove de Julho, UNINOVE, São Paulo, SP, Brazil 